\title{
Article \\ Which High-Speed Rail? LARG Approach between Plan and Design
}

\section{Francesco Russo}

\section{check for}

updates

Citation: Russo, F. Which High-Speed Rail? LARG Approach between Plan and Design. Future Transp. 2021, 1, 202-226. https:// doi.org/10.3390/futuretransp1020013

Academic Editor: Laura Eboli

Received: 8 May 2021

Accepted: 12 July 2021

Published: 29 July 2021

Publisher's Note: MDPI stays neutral with regard to jurisdictional claims in published maps and institutional affiliations.

Copyright: (C) 2021 by the author. Licensee MDPI, Basel, Switzerland. This article is an open access article distributed under the terms and conditions of the Creative Commons Attribution (CC BY) license (https:// creativecommons.org/licenses/by/ $4.0 /)$.
Dipartimento di Ingegneria dell'Informazione, delle Infrastrutture e dell'Energia Sostenibile, DIIES, Mediterranea University of Reggio Calabria, 89124 Reggio Calabria, Italy; francesco.russo@unirc.it

\begin{abstract}
Of the approximately 100,000 km of High-Speed Rail (HSR) lines in the world today, half are in operation and half are planned or under construction. The implementation of HSRs are planned in various countries with different characteristics to pursue different objectives. Today, the results are known, and therefore, the differences between the planned and achieved objectives can be verified. Italy is one of the countries that first built an HSR, and now, at the national planning level, Italy has decided to implement an HSR in Southern Italy. The problem is therefore not "whether" to realize an HSR but "which" type of HSR to realize. Italy is an important case study at the international level because it is possible to extend the HSR network in three different ways: upgrading existing lines by increasing the speed to $200 \mathrm{~km} / \mathrm{h}$, building a new line with speeds of $300 \mathrm{~km} / \mathrm{h}$ with heavy freight trains, and building a new line with speeds of $300 \mathrm{~km} / \mathrm{h}$ without heavy freight trains. The problem is how to find the best alternative in order to pursue sustainable development while considering national planning. To solve this problem, at the intermediate level between planning and design, the theoretical Lean, Agile, Resilient, Green (LARG) paradigm is proposed and applied. This approach can be extended to all countries that are launching massive and expensive programs to construct HSR lines or to upgrade existing lines.
\end{abstract}

Keywords: high-speed rail; LARG paradigm; sustainable development; planning

\section{Introduction}

According to the data (updated 2020) from the Union Internationale des Chemins de fer [1], there are many High-Speed Rail (HSR) lines in the world: 52,484 km in operation, $11,960 \mathrm{~km}$ under construction, 11,383 km planned, and 28,586 km planned over the longer term, with a total of $104,413 \mathrm{~km}$.

The largest network today is in China $(35,388 \mathrm{~km})$, followed by Spain (3330), which has overtaken Japan $(3041 \mathrm{~km})$ and then France $(2734 \mathrm{~km})$. The HSR network in Italy (newly built lines) includes the Turin-Milan-Bologna-Florence-Rome-Naples-Salerno line (in operation) $(856 \mathrm{~km})$ and the Milan-Venice line, which is in operation $(65 \mathrm{~km})$ and under construction $(124 \mathrm{~km})$.

The definition of a high-speed rail is not universal and is ambiguous due to the original formalization by the European directive [2,3].

The directive in Annex I states that high-speed lines comprise the following:

Specially built high-speed lines equipped for speeds generally equal to or greater than $250 \mathrm{~km} / \mathrm{h}$;

Specially upgraded high-speed lines equipped for speeds of the order of $200 \mathrm{~km} / \mathrm{h}$; and Specially upgraded high-speed lines that have special features as a result of topographical, relief, or town-planning constraints, for which the speed must be adapted to each case.

The directive does not provide other specifications. It is useful to recall the directive proposed by the UIC, consistent with the European standard [4].

International research on HSR has advanced since many experimental results are now available thanks to the operation of networks around the world, totaling 50,000 km. 
One of the most important components is that of the energy impact, as that of the system can be run on renewable energy sources and can be used as an alternative to trucks for the transportation of goods and to aircrafts for the transportation of passengers. Thus, renewable energy becomes central both because it can be fed directly into the grid and because hydrogen propulsion can replace diesel.

It is interesting to recall the work developed for the interaction of transportation and energy in the USA [5]. That paper presented a long-term plan to optimize investments simultaneously regarding the transportation and electric infrastructure systems in the USA. That paper considered the impact of HSR investments on interstate passenger transportation, fuel and electricity consumption, and the 40 -year cost and carbon dioxide $\left(\mathrm{CO}_{2}\right)$ emissions. The results show that a significant HSR penetration can lead to a reasonable decrease in the national $\mathrm{CO}_{2}$ emissions and costs in the long run.

Another important impact is that on social inclusion. Various works are available that have investigated this topic. It is useful to recall the comparison between the European railway systems in the work by Fraszczyk et al. [6], in which the role of accessibility for passengers in more rural and excluded areas was highlighted, which can be projected onto the national scale to include large areas that lack development. The authors highlighted that an increase in accessibility is an important issue, as not only would this increase the quality of life for the people living in villages and towns that are under developed but also this could potentially generate extra income from travel (employment, education, entertainment, etc.) for railway companies. This theme is central to countries with large areas that are to be integrated.

An interesting comparison is the one between HSR systems already built in Europe (France and Spain) and Asia (China and Japan) to obtain indications for an HSR corridor planned and built in a developing country, Saudi Arabia. That paper, which analyzed the technological advances in HSR [7], indicated the possibility of applying the concepts of the European system while considering the similarities in terms of geography, population distribution, and distance, highlighting the benefits of technological advances from other countries. The conclusions were important because they extended the results of the aforementioned work to the national scale [6] with respect to the integration of less developed areas.

Important research papers have been produced in which HSR systems have been analyzed in depth in order to realize them in new contexts. Similar to the work related to Saudi Arabia mentioned before, it is useful to cite an in-depth research work that considered the possibility of building an HSR in California [8]. Some elements that have conditioned the success of high-speed rail services in Europe and Asia emerged from this work: (1) winning the competition with other modes of transportation for connections between 150 and $800 \mathrm{~km}$, (2) dense centers of activity within walking distance of future station sites, and (3) seamless connections between rail and local public transport networks. In other words, the HSR must represent the fundamental axis of an overall system for the sustainable mobility of passengers. Various works have been presented that have considered the economic aspects related to the implementation of an HSR in Europe; however, it is not possible to carry out an exhaustive discussion, and it is rather useful to recall the work coordinated by De Rus [9], who, similar to other authors, helped clarify many aspects related to investments into HSR projects, which require public funds, by analyzing how important economic and social benefits can be achieved.

One of the most important analyses on what has occurred worldwide in the context of HSR was the one carried out by EIM, the European Association of Managers of Railway Companies. The 2008 EIM report was entitled European Railway Technical Strategy: Technical Vision to guide the development of Technical Specifications for Railway Interoperability (TSIs) [10]. The report showed that one of the best ways to increase the efficiency of railway systems is to identify the different demand segments and to differentiate the lines in relation to them while continuing to use standardized components. 
The report [10] proposed differentiation from a strategic perspective, identifying three main classes in national networks: a multi-purpose core network (under $250 \mathrm{~km} / \mathrm{h}$ ), a high-speed network (at $250 \mathrm{~km} / \mathrm{h}$ or over), and a heavy freight network (at $100 \mathrm{~km} / \mathrm{h}$ or under). Based on a strategy of specifying railway networks and their full interoperability, EIM [10] proposed a strategic vision of the main characteristics that the individual lines should have by the year 2035. In particular, for the High-Speed Passenger, a maximum speed of $360 \mathrm{~km} / \mathrm{h}$ has been proposed from the perspective of potential business needs.

The difference highlighted by the EIM [10] is in line with what was previously seen in the European directive $[2,3,11,12]$ and in the UIC report [4], but it drives the choice between updating and building a new line from demand.

From an analysis of the international framework, the benefits of HSR clearly emerge, so much so that all countries are developing massive programs for the construction of new lines or upgrades of some existing lines.

Italy is one of the countries that first built an HSR. The development of transport planning documents on a national scale has established that an extension of the high-speed rail network to Southern Italy is one of the country's priorities. This decision was made at the beginning of the 21st century [13] and confirmed in recent planning documents, up to the PNRR prepared for the Next Generation EU [14].

The problem that arises in Italy is that of having an HSR system extended to the entire national territory but not limited to some main sections built in economically developed areas of the country. Italy has since transitioned from the planning phase to the programming phase and is starting to design a line that has the technical and geometric characteristics similar to those of the other existing Italian lines. They have to choose between two alternatives:

- $\quad$ upgrade the existing line by increasing the speed to $200 \mathrm{~km} / \mathrm{h}$ or

- build a new line with characteristics similar to those of the lines already built in Italy in terms of speed $300 \mathrm{~km} / \mathrm{h}$ with the use by heavy freight trains (750 mt, 2000 tons).

This completion must take place considering, on the one hand, the objectives achieved (or not) in Northern Italy and, on the other, the costs to be incurred with respect to the economic, social, and environmental changes induced by the HSR for sustainable development of Southern Italy.

From the considerations about cost efficient and effective, the possibility of considering a third alternative arises, which is new for Italy but which has been pursued in other European countries such as France and Spain, and in non-European countries from China to Saudi Arabia and Morocco. Italy is an important case study at an international level because it is possible to extend the HSR network by considering a third alternative:

- build a new line with characteristics similar to those of the new lines built in other countries with a speed design of $300 \mathrm{~km} / \mathrm{h}$ and without the possibility of being used by heavy freight trains.

Therefore, the problem that arises in Italy is not "whether" to build a high-speed rail line in Southern Italy, because this has already been decided upon, but "which" high-speed rail line to build. It is therefore necessary to use a reference paradigm that allows us to compare the aggregate characteristics of the three alternatives. The problem is building a theoretical approach that is more specific than those used for national planning, such as the multi-regional input output (MRIO) or CGE [15], and less specific than those used for the evaluation of projects such as the consolidated Benefits Costs Analysis (ABC). It is therefore necessary to find the best solution among the three alternatives outlined in order to pursue the developmental sustainability objectives.

The approach carried out can be extended to all countries that are launching massive and expensive programs for the construction of high-speed lines or for upgrading existing lines. A European reader, researcher, or technical planner may be interested in the topic covered in this paper because all EU countries are developing TEN-T rail projects; thus, this topic affects all countries. The three alternatives for HSR can be considered in all 
countries. In fact, as mentioned above, the MRIO models are extremely valid at the national or interregional planning levels and give valid answers to the question of whether an HS line should be created, as in Italy, while the ABC models are very useful for choosing between design alternatives, as the structural characteristics of the HS line have already been defined. Having an intermediate model between MRIOs and ABCs can make an important contribution to deciding on the best choice.

Section 2 outlines the international objectives set for the planetary future defined in the 2030 Agenda, which can be considered directly connected to the construction of an HSR line based on the costs and benefits at the national strategic level, both aggregated, found in the realized HSR.

In Section 3, the theoretical LARG paradigm is proposed, starting from a synthesis of the literature concerning the constitutive paradigms: Lean, Agile, Resilient, and Green. Implementation in the most advanced industrial systems is recalled, verifying the possibility of applying the LARG paradigm to transport systems and to large civil railway infrastructures. The LARG paradigm allows us to develop a comparative evaluation between different alternatives considering the level of detail [16] at which one is working, which is between the end of planning and the beginning of design.

Section 4 examines the use of the LARG paradigm in the planning of a large railway infrastructure in Southern Italy.

The three alternatives presented above are compared. First, the hypothesis of the existing line adapted is analyzed. The hypothesis of a new HSR line built with the characteristics already used in the Italian network is therefore evaluated. The possibility of creating a new line based on the LARG paradigm is then analyzed.

The conclusions verify how the LARG perspective allows for the identification of the most competitive and functional infrastructure.

\section{International and National Strategy for Sustainable Development}

\subsection{International and National Strategic Goals}

The construction of an HSR in Southern Italy qualifies as sustainable development for the territories it passes through.

The first definition of sustainable development was coined in 1987 in the Our Common Future report, better known as the Brundtland Report [17], which highlights the three main themes of sustainable development: society, the economy, and the environment.

Almost 30 years later, in September 2015, 193 UN member states approved Transforming our world: the 2030 Global Agenda for Sustainable Development $[18,19]$ document. This document identifies 17 Goals for Sustainable Development. It is useful to recall the centrality of some general goals and related specific targets.

International goals must be the basis of national and international plans, such as for national planning in Italy's latest document [14] and for the planning of TEN-T networks in the EU [11,12]. Table 1 summarizes the main issues in Italy during the development of the national plan. In Table 1, the topics are collected in an extremely concise and nonexhaustive way, with reference to the goals of the 2030 Agenda, directly linkable to the HSR. The goals pursued, the current situation regarding HSRs, and the expected outcomes are reported. 
Table 1. International goals, actual situations, and planned outcomes.

\begin{tabular}{l} 
Goals and Formal Statements \\
\hline 7. Ensure access to affordable, reliable, sustainable, and \\
modern energy systems for all
\end{tabular}
modern energy systems for all

\section{Actual Situations for the Areas \\ Considered and Relevance for Goal}

Transportation from Sicily and Calabria to the capital is primarily by air transport, with a high impact on GHGs
8. Promote sustained, inclusive, and sustainable economic growth; full and productive employment; and decent work for all
Certain areas of Southern Italy severly lag behind in development compared to the rest of Italy and in the EU, with a per capita GDP value below half that of other parts of the country.

\author{
Outcomes with HSR in \\ Pursuit of the Goal
}

The rail system is designed to constitute a valid alternative to air transport. The railway system allows for the use of renewable energy, improves energy efficiency, and guarantees the use of clean energy and complete control of emissions.

The HSR, considering the results in other areas, promotes necessary GDP growth; the development of higher standards of productivity through technological progress, job creation, full employment for women and men, and full employment for young people and people with disabilities; and a reduction in the number of young people who are out of any study cycle but umployed.

The HSR aims to build quality, reliable, sustainable, and resilient infrastructures. It is also worth recalling the need for equitable access provided by an HSR for all and therefore not only for citizens of economically rich regions but also, even more so, for citizens of economically weaker regions.

The first inclusion has the possibility of being pursued starting with the construction of an HSR infrastructure that allows for growth at a rate higher than the national one. The second inclusion regards a large part of the Italian population (about 10 million), marginalized by the main development progress of the country and of the EU.
10. Reduce inequality within and among countries.
Social inclusion in Southern Italy takes on two aspects: the inclusion of lower income social groups and the inclusion of areas of Southern Italy as a whole, marginalized with respect to Italy and the EU across the nation.

A complete analysis of the plan is reported in the Italian PNRR [14]. The PNRR planned and programmed the development of the HSR network in Southern Italy; in this paper, the decision to build an HSR was already made, and as mentioned above, the issue becomes "which" HSR to build, from the baseline scenario of adjusting a pre-existing line.

It is necessary to have a paradigm of reference that, between the final planning phase and the first design phase, allows for the identification of optimal alternatives with respect to international goals without particular planning insights. 


\subsection{Aggregate Strategic Factors Linked with HSR}

To be able to compare the three macro-alternatives of HSR, it is necessary to evaluate some aggregate quantitative values, without going into the details that are typical of the design phase. In fact, an $A B C$ with the highest level of detail can be used in the design phase to make a choice regarding the alternatives. The three aspects that need to be known, in terms of quantitative values, are accessibility with and without HSR, increase in GDP, aggregate cost of the macro-alternatives HSR, and demand affected by the new infrastructure. In summary, accessibility is a measure of social inclusion, GDP is a measure of economic development, cost is a measure of investment efficiency, and modified demand is a measure of both the effectiveness of spending and the overall environmental impact. These three elements constitute a basis for their subsequent evaluation, but it is also necessary to consider, as will be seen below, the environmental components. These must be considered not only in an external and parallel evaluation process but also in the paradigm evaluated for pre-feasibility.

The accessibility of railways in Sicily, Calabria, and Basilicata are extremely lacking, at the national, interregional, and regional scales. An analysis of the accessibility evolution related to HSR with specifications for different regions in China was developed by Wangtu et al. [20]. The market share of an HSR depends on the hours of travel. Rothengatter [21] reported that an HSR (100\%) is primarily used compared to a plane for up to $3 \mathrm{~h}$ of travel and is still significant for up to 4 and a half hours (50\%). Therefore, a $3 \mathrm{~h}$ threshold is used for travel between regions.

In Russo [22], railway accessibility was evaluated by means of connection times, from the cities of the macro-regions Northern and Southern Italy to the barycentric cities of the two macro-regions, analyzing whether the time taken is less than $3 \mathrm{~h}$.

For the Southern macro-region, the time taken to travel between the regional capitals and the metropolitan city of Reggio Calabria were considered. For the Northern macroregion, the times taken to travel between the regional capitals and the metropolitan city of Bologna were considered. No regional capital without the HSR South can be reached from Reggio Calabria, and all of the regional capitals (except Aosta) can be reached from Bologna (Table 2). With the realization of HSR South, all of the region capitals of Southern Italy become accessible.

Table 2. Accessibility of Southern and Northern Italian regions.

\begin{tabular}{|c|c|c|c|c|}
\hline $\begin{array}{l}\text { Region Set } \\
\text { Considered }\end{array}$ & Region Set Center & $\begin{array}{c}\text { Time from Center to } \\
\text { Region Capital Less } \\
\text { Than } 3 \mathrm{~h} \text { without } \\
\text { HSR South }\end{array}$ & $\begin{array}{c}\text { Time from Center to } \\
\text { Region Capital More } \\
\text { Than } 3 \mathrm{~h}\end{array}$ & $\begin{array}{c}\text { Time from Center to } \\
\text { Region Capital Less } \\
\text { Than } 3 \text { h with } \\
\text { HSR South }\end{array}$ \\
\hline Northern regions & Bologna & $\begin{array}{c}\text { Trieste, Udine, } \\
\text { Venezia, Milano, } \\
\text { Torino }\end{array}$ & Aosta & $\begin{array}{c}\text { Trieste, Udine, } \\
\text { Venezia, Milano, } \\
\text { Torino }\end{array}$ \\
\hline $\begin{array}{l}\text { Southern } \\
\text { regions }\end{array}$ & Reggio Calabria & - & $\begin{array}{c}\text { Palermo, Potenza, } \\
\text { Bari, Napoli }\end{array}$ & $\begin{array}{l}\text { Palermo, Potenza, } \\
\text { Bari, Napoli }\end{array}$ \\
\hline
\end{tabular}

In terms of the social sustainability of development, Southern Italy is on a downward trend regarding development in the next century, with an impossibility for Southern Italy to become integrated within it Lack of accessibility is one of the central issues for the dramatic demographic fall that Southern Italy is facing, and therefore, Italy is expected to see an average loss of $25 \%$ of the population in the next decades (to 2065). Calabria will lose 500,000 inhabitants, and Sicily will lose more than 1 million. Basilicata lost 1\% of inhabitants in one year. These demographic scenarios were obtained by assuming that, in the worst case, the current situation of accessibility is maintained. The increase in accessibility modifies the national demographic and makes it possible to significantly reduce the loss in population. 
Accessibility is one the pillars on which the planning documents have established the extension of the high-speed rail network to Southern Italy as one of the country's priorities on a national scale [14].

In the same way, the problem of the Sicilian railway network, currently being rebuilt or in planning, must be clarified. It seems necessary to verify the role of a $300 \mathrm{~km} / \mathrm{h}$ HSR that historically modifies the development of Sicily since the creation of the city, with 2 million inhabitants on the Palermo-Catania axis and by integrating the areas the HSR would cross.

We directly highlight the theme of economic sustainability using the most recent research on the impacts of HSRs in Italy [23] and in the world [24-26].

To understand the benefits of a $300 \mathrm{~km} / \mathrm{h}$ HSR for the GDP, it is sufficient to recall real data related the last 10 years of use of the HSR in Italy [23]. It emerged that, in the territories with the HSR, the GDP grew by 7 points more than in territories that do not, both in Northern and Southern Italy. The authors analyzed the impacts of HSR on interregional equity, on economic growth, and on accessibility. That paper reported GDP growth due to HSR. The HSR generated $2.6 \%$ more GDP in 10 years across the country. Specifically, the HSR directly increased the GDP in affected areas from a minimum of $5.6 \%$ to a maximum of $11.8 \%$.

If the hypotheses were sufficient (i.e., only the presence of HSR, with all other conditions being equal), the construction of the HSR in Southern Italy should produce a differential increase within 10 years of 7 percentage points of GDP in the cities linked by HSR and in the territories reachable in two hours from cities that have HSRThe significant increase in accessibility and the growth of GDP per capita generate a profound modification of the demographic curve. Assuming that HSR realizations are very fast, the demographic curve goes from negative to positive as it has always been in Southern Italy, particularly in Calabria and Sicilia.

Similar results are presented for HSR in China $[26,27]$, where it was verified that, in all Chinese regions, the development of HSR between 2002 and 2013 generated a positive economic impact of about $8 \%$. The GDP growth rate related to railway infrastructure investment was significant in the less developed areas of the southwest and relatively modest in the developed regions of the east. However, considering the Chinese case from a different point of view, the China Railway Corporation has a significant debt problem due to their large investment into the HSR construction [28,29], and if this situation does not change, the HSR program will slow down, with a crucial impact on the sustainable development of rural areas

In the development of the HSR analysis in China, it was also verified that the HSR is chosen as the main mode of transportation compared to the conventional one, even in less developed regions, ensuring territorial equity between the different regions.

A comparative analysis of network efficiency with respect to spatial equity was carried out by Monzon et al. [24]. From this analysis, it emerged that pursuing only the efficiency of an HSR network induces heavy effects of spatial polarization, with negative impacts on territorial equity between the areas that are equipped with HSR and those that remain without.

On the social level, the realization of an HSR will increase employment in Southern Italy, estimated at 10,000 employees per year for 10 years.

The repercussions will be equally important for Northern Italy, with a formidable economic impact on the entire productive structure. From the economic analyses conducted in the last 10 years, it emerged that, for every 100 EUR invested into Southern Italy, about 40 EUR goes to Northern Italy and only 50 EUR remains in Southern Italy. Additionally, from this point of view, investments into Southern Italy would be a great for the entire country. 
Workers fall between social and economic development because, on the one hand, it increases the income of families by raising the average value and, on the other, it directly affects work, which is always a particularly important variable, even more so in Southern Italy, where the 2008 crisis combined with that of the COVID-19 pandemic produced a social and economic disaster.

An analysis of the demand must be carried out in aggregate form during the elaboration of the general planning tools and in disaggregated form during the project elaborations. Following the approach used in this paper, an intermediate one between the most advanced planning levels and the first design level must be used, the one relating to pre-feasibility.

- The demand for HSR has three main components [30]:

- diverted demand

- from other modes (e.g., car, air, and bus) to HSR and

- from other rail services to HSR;

- induced demand, which can be

$\circ \quad$ direct (e.g., changes in trip frequency) and

- indirect (e.g., increase in mobility due to changes in lifestyle and/or land use; and

- economy-based demand growth.

It is useful to recall the work of Givoni and Dobruszkes [25], who analyzed the change in demand from air to HSR with an ex post analysis of the European and Japanese HSR networks. The analysis shows that significant changes, greater than $50 \%$, occur when the HSR provides connections in the order of magnitude of $3 \mathrm{~h}$.

For the HSR system operating in Italy, it was found [23] that 7 million pax/year moved from traditional railway services to HSRs and that 19 million moved from other methods of transportation (private car, buses, and air) to HSR, with 17 million generating this demand (Table 3). For the development of this work, particular attention was paid to the demand for HSR, which currently uses air services as it represents the safest route for the new line since it is a demand that already exists.

Table 3. Passengers/year from Calabria and East Sicilia to Rome and vice versa, in millions.

\begin{tabular}{|c|c|c|c|c|}
\hline & Italian HSR [30] & $\begin{array}{c}\text { Calabria } \\
\text { Forecasted with HSR }\end{array}$ & $\begin{array}{c}\text { Sicilia } \\
\text { Forecasted with HSR }\end{array}$ & $\begin{array}{c}\text { Calabria and Sicilia } \\
\text { Forecasted } \\
\text { with HSR }\end{array}$ \\
\hline $\begin{array}{l}\text { From other modes } \\
\quad \text { (air services) }\end{array}$ & 19.0 & 1.08 & 1.28 & 2.36 \\
\hline From other rail services & 7.0 & 0.39 & 0.46 & 0.85 \\
\hline Generated demand & 17.0 & 0.98 & 1.17 & 2.15 \\
\hline Total HSR demand & 43.0 & 2.45 & 2.91 & 5.36 \\
\hline
\end{tabular}

A modal choice model was applied. It has been hypothesized that user choices can be represented with a random utility model using logit formulation. The model was made considering the flows measured in railway services and in pre-pandemic air services in 2018, leaving the model calibrated for movements on a national scale in Italy [31]. We need to note that, by considering only air and train flows, a lower value of demand to change to HSR use is estimated, assuming that there is no significant modal change for users who currently use cars and buses.

The change is in the specific modal attributes that have a higher utility for rail services than for air services, representing the quality of the service offered by HSR trains. This result confirms what has been achieved in other countries [32,33]. 
The daily passenger demand for the connection Calabria-Roma is reported in Table 3. The model was therefore also applied to the Catania-Rome air routes for passengers using the Catania airport. With the values obtained, a demand derived from air transport of the order of 2.36 million pax/year was obtained, and this value is in line with the 2.1 million trips obtained in the first years of operation of the HSR in Italy [34].

On the basis of the value obtained for the demand derived from the other modes (air), using the same ratios obtained in Italy [30], the values of demand derived from existing railway services and the demand generated, both induced and due to economic growth, were estimated (Table 3 ).

It is important to note that the total value obtained (about 5 million passengers/year) is a lower bound, and it does not consider three areas that are affected by the construction of the new line: the southern part of Campania, Basilicata, and the western part of Sicily. It should also be considered that, in the estimate made, all inter-regional and intra-regional movements permitted by the new line are not considered.

HSR assumes defined cost characteristics, obtainable from information on the lines built half a century ago and updated to current values.

It is useful to recall the costs of HSR as reported in aggregate form in international literature, dividing them into two categories: operating and maintenance costs, and construction costs.

The operating and maintenance costs of HSR are substantially identical in a wide range of speeds, being related to the cost of the trains used, their maintenance, and their energy consumption.

Instead, it is necessary to specify the construction costs because the economic feasibility of HSR depends on them. We explicitly refer to the construction of new lines and not to lines adapted for the HSR [2,3].

The construction costs of the HSR lines are high and very variable from country to country. Considering the costs of European countries, it ranges from a minimum of 8-20 million euros per $\mathrm{km}$, in Spain, to a maximum of 14-65 million euros per $\mathrm{km}$, in Italy; in the literature and on the web, there are many works that report the costs calculated under different socioeconomic conditions for different countries where an HSR was carried out, considering different factors within the cost. A common feature of all international literature is that the cost in Italy is 2 to 3 times that of other countries very similar to Italy in economic and social status, such as Spain.

The cost of an HSR line is influenced by multiple factors, which depend on the orographic conformation, the degree of urbanization, and more generally the economic context and decision-making processes of the country in which it is built. Table 4 shows the construction costs calculated by the European Court of Auditors reported in Annex IV: Calculated Key performance indicators [35]. These values show that construction costs in Italy are double those of other European countries.

Table 4. Total cost of an HSR in Europe in millions of euro per kilometer [35].

\begin{tabular}{ccccc}
\hline Total Cost & Spain & France & Germany & Italy \\
\hline Work Completed $/ \mathrm{km}$ & 12 & 15 & 13 & 28 \\
$\begin{array}{c}\text { Work Completed and } \\
\text { under Construction/km }\end{array}$ & 14 & 15 & 15 & 33 \\
\hline
\end{tabular}

The costs of the HSR lines built in Italy were among the highest in the world, and this slowed the construction of new lines, particularly in Southern Italy. The cost of building HSR lines in Italy is very high due to a number of factors, which have led, according to some estimates, to an extra cost of 16-23 million euros per kilometer compared to the French and Spanish networks [36]. The main factors are listed below. 
The Italian system was created for high speeds and high capacities, with the intention of allowing for heavy freight traffic on the new lines; this has led to very restrictive geometric characteristics (maximum slope of 12-15 per thousand and planimetric radii of $5550 \mathrm{~m}$ compared to slopes of 35 per thousand and radii of $4000 \mathrm{~m}$ in France); the adaptation of the routes to the ground was more difficult and required the construction of bridges and tunnels for greater extensions. The greater load per axle required by heavy freight traffic compared to passenger traffic (22.5 vs. 18 tons/axle) led to higher construction costs for the viaducts. Due to the orography of the area, there is a high incidence of tunnel and viaduct sections and, therefore, the increase in cost per unit of viaduct length translates into a much higher overall cost.

The Italian system foresaw a strong integration between the new lines and the historical network; this required the construction of a large number of interconnections (24 from Turin to Naples), with a total extension of $76 \mathrm{~km}$ of double track connections. The connection to the metropolitan networks required major restructuring of the railway junction lines and the adaptation/construction of new stations, constituting ongoing work.

The crossing of highly urbanized areas has led to high costs in acquiring the worksites and the need for redevelopment of the territory and road networks (new roads for $400 \mathrm{~km}$, redevelopment of existing roads for $700 \mathrm{~km}$, and motorway variants by $40 \mathrm{~km}$ ).

The construction works were awarded through direct negotiation between the State and the General Contractors; this has resulted in increased costs with respect to the assignment through tenders.

\section{Theoretical LARG Paradigm from Industry to Transport System and Infrastructures}

\subsection{Definition of the LARG Paradigm}

The consolidated tools available for the planning and design phases of transport infrastructures are particularly useful because they allow the public decision-maker to make informed decisions.

In the case of construction of particularly important transport infrastructures, it may be equally useful to insert further information that can improve public decisions. The new tool must be placed downstream of the planning tools, such as the MRIO models, and upstream of those of feasibility design, such as the ABC.

It is possible to construct a reference paradigm which, among the phases mentioned, allows us to identify which macro-alternative to use with respect to international objectives without particular design specifications. This section presents a paradigm that first established itself as a reference paradigm in the automotive industry and is now used also in other segments of advanced industrial production.

To remain competitive and to strengthen market penetration, large companies must carefully identify priorities [37], in the organization of both internal and external logistics, where the schematic difference between internal and external logistics consists in the fact that, when the logistics are internal, planning and management related to the flow of materials are internal to the single production system, usually defined by the plant. If the logistics are external, the logistics system (and therefore all planning and management) is related to the overall production system, which therefore considers both all plants and all warehouses, with all of the processes and paths being carried out to obtain the final product available on the market. External logistics are systematically and increasingly confronted with the transport sector, becoming interdependent sectors, becoming two interdependent sectors. For complementarity, and therefore to specify the choices belonging to each sector, a debate still in progress is considered $[38,39]$. Today, the best performing companies consider the supply chain. Logistics is located within the supply chain, which has a transversal function within the company, where it integrates logistics with other important activities such as purchases and sales. In relation to this expansion of planning and management, the supply chain considers the flow of materials and those of values and information. 
The factors that, in the literature, are identified as important in the relationship with the market are costs, quality, delivery times and flexibility, and ability to respond to demand [40].

The theory of business management has developed over time as different paradigms that allow a company to be competitive, starting with the historical "Fordism" paradigm that saw the birth and development of the large automotive industry.

The transformation of the relationship with consumers and the increasingly present model just in time have forced companies to review their organizations according to the final consumer. In this context, external logistics has become one of the most important keys for the development of large industrial systems.

The experiences of different companies have led to the synthesis of four paradigms that, today, prove to be the most efficient for directing the strategic choices of the company and therefore their translation into operating models.

In the field of external logistics, the following operating models are adopted:

- Lean leads to cost reduction and quality improvement;

- Agile allows us to improve the ability to respond to demand, reducing delivery times and improving the flexibility of services;

- $\quad$ Resilient leads to better preparations for high probability risks with modest effects and particularly serious low probability risks, managing to overcome the effects of events earlier; and

- Green requires considering both the components related to the construction process and those related to use, extending the paradigm to various safety aspects.

To better address the problems given by the need to be competitive, companies have applied the individual paradigms in various ways: lean, agile, resilient, and green.

\subsection{LARG Paradigm in the Industry}

The scientific literature reports many works related to the application of a single paradigm in big company. "Toyotism" in the 1950s first structured internal logistics and then the entire production using the Lean paradigm as a reference. The paradigm that was translated into an operating model has become the basic organizational system for industrial production that was subsequently implemented by other industries, borrowing it from the automotive sector [41]. The Lean paradigm was updated in the first 20 years of the 21st century, proposing it as a reference for large transport infrastructures.

In the last twenty years, the reorganization of industrial production has imposed a decisive role for external logistics and an ever-greater integration with the internal one relating to the production of a single plant. There are case studies that have seen the integration of pairs of paradigms in the experimental field of external logistics.

The implemented pairs of which some results are present in the literature are lean and agile, lean and green, resilient and agile, and resilient and green.

In the context of the application of two paradigms, the literature has paid attention to convergence and divergence (similarities and differences, overlaps, or contrasts) that can be generated between the couples considered.

As an example of convergence, the one between lean and agile paradigms can be cited in the supply chain, for which the term of leagility was coined [42].

As an example of divergence, the lean and green pair in the implementation of just in time for shipments of small quantities can be cited: the lean operating model can lead to an increase in shipments in contrast to the green model, which requires a reduction. As the distance between the origin and destination of the movements increases, the lean and green paradigms can be increasingly in conflict, making the connected choices divergent.

In the experimental reality of large companies, the implementation of three paradigms simultaneously was also considered. It can be highlighted how the minimization of warehouse stocks favors the lean and agile paradigms, but by increasing the vulnerability of the logistics chain, it puts in place conditions of reductions in resilience, which instead requires an increase in inventories. 
In recent years, the industrial management of the most advanced and best performing companies in the automotive sector [43] has implemented the four paradigms simultaneously by identifying a hybrid approach with the acronym LARG.

Today, many companies are adopting LARG by translating it into operating models. In moving from ex ante paradigms to operational models, there may be concordances and discrepancies between the paradigms constituting the LARG; it is necessary to find the best tradeoff between the different basic paradigms in order to increase competitiveness and to improve the performance of a given industrial system [44-46].

For an updated overview of the literature dealing with the four paradigms, see Divsalar et al. [47] and the bibliography reported therein.

It is of particular interest to mention the work of Azfar et al. [48] because it deals with the evolution of a supply chain in relation to the evolution of the main transport system on which it operates. In this sense, it is the closest paper to our study of the LARG paradigm for a railway infrastructure. Specifically, the authors examined the LARG paradigm by applying it to the China Pakistan Economic Corridor. The paper presents a detailed analysis of the synergies and divergences related to the application of the four component paradigms, starting from the advantages and disadvantages of each alternative corridor to the one considered.

\subsection{LARG Paradigm in Transport Systems and Railway Infrastructures}

In light of the results obtained by the major automotive industrial players [43], passing from Lean to LARG, it is useful to analyze the possibility that the latter is extended from industrial production to that of transport systems and therefore of big civil infrastructures.

To this end, it is interesting to investigate how to develop feasibility and therefore design and construction with innovative features compared to traditional infrastructural, focusing on the following four themes:

Cost reduction and quality improvement (lean);

Adaptation to the requests of the different demand segments (agile);

Effective response to risk conditions of different degrees of probability (resilient); and Environmental promotion and reduction in ecological damage during construction and in operation (green).

The problem that arises is that a large railway infrastructure is built. As mentioned above, this problem is examined in depth subsequently, passing from the planning phase to the design phase. It is appropriate to introduce a further intermediate phase in which the choice between the three macro-alternatives is examined in depth. It is useful to consider that the decision-maker in Italy is a public company (RFI Italian railway network), which develops the implementation in agreement with the Ministry of Transport. Therefore, a paradigm that reconciles the two needs is needed: public interest for large transport infrastructures and the interest of a large public company to maintain correct balance between economic, social, and environmental budgets. The LARG paradigm allows us to consider the various criteria crucial for public interest to choose between the three macroalternatives. The generalized LARG paradigm considers all four constitutive paradigms simultaneously [49].

The Lean paradigm focuses on reducing costs through the continuous elimination of waste and all activities without added value. For the case in question, the analysis must be developed by considering the potential activities (business) that were foreseen in the HSR_HC. It is therefore necessary to identify the activities that, among the potential ones, hypothesized ex ante, did not produce any ex post added value. On this basis, it is possible to identify and eliminate important factors foreseen ex ante in the HSR_HC but transformed into waste ex post.

The hypothesized value-added activities were those of the passage of heavy freight trains. To date, no heavy trains have passed on the HSR_HC lines and therefore no value has been produced. The question of building lines for heavy freight trains, which are then not used, seems very interesting. It is necessary to carry out a further political discussion 
and a future agenda on the revaluation of national infrastructure investments in Italy. The Italian discussion allows us to contribute to the international debate on future HSR with European institutions and with the countries that are planning new high-speed lines both between planners and researchers. The hypothesis of the passage of heavy freight trains has generated an estimated cost increase of between $50 \%$ and $100 \%$ compared to a line with only passenger trains or fast logistics [50].

The Agile paradigm is developed with an analysis of the components of demand that can realistically use the infrastructure and therefore the potentially operational services [51]. It is necessary to examine all of the potential segments regarding demand and their specific characteristics, starting from the passenger demand for HSRs throughout the world and the potential ones that can still be developed for the characteristics of Southern Italy. It is necessary to study what are the decisive characteristics that determine the growth of trends; the rate due to modal change, in particular in comparison with air transport; and the demand generated by innovative features of the new system.

The Resilient paradigm is developed starting from a definition of the risks linked to the infrastructure and the services that operate on it, considering the occurrence, vulnerability, and exposure of each risk. From the formulation of the risk, the development of the Resilient paradigm requires careful study of the connection between risks and events and, therefore, of limiting the effects by acting on the different components and by restoring the state prior to the event [52].

The Resilient paradigm must be explored both with respect to the infrastructure and with respect to the role it assumes in the economic context, managing to integrate restarts, as traditional infrastructures are often unable to perform. The Resilient paradigm must also be developed with respect to operation, studying all of the components subject to risk, both for safety in terms of safety and security, and for the regularity of the service based on traffic control. Regularity needs to be studied because it is severely hampered by heterotachic regimes due to the intermixture of high-speed passenger trains and heavy freight trains, as well as intercity and regional trains [53].

The Green paradigm explores the environmental sustainability of the intervention in all its phases, from design to the end of its life cycle and the reduction in damage potentially directly or indirectly caused by its construction and its operation. The implementation of the Green paradigm is particularly important in Italy, and it is useful to recall the construction process of the Turin-Lyon HSR. On this line, the impacts on the environment were particularly high, and following the first design, the public debated possible improvements in the impact of its construction. Similarly, it is necessary to study the ability of an HSR line to reduce air traffic by drastically reducing environmental impacts without restricting mobility. For this paradigm, it is interesting to recall the Swedish research program "Green Train", with the overall objective to define an economical, flexible, and environmentally friendly train concept [54].

\section{LARG Paradigm Application to an HSR Line}

\subsection{LARG Approach for the Comparison of Railway Alternatives}

The LARG theoretical paradigm can be used to carry out an HSR analysis at the last level of planning, before proceeding to the design phases.

The use of the LARG paradigm requires an analysis of the territory in which the infrastructure is to be built.

The theme of the territory differentiates the application of the theoretical paradigm between applications in industrial production and applications in a civil infrastructure. Industrial production is, by nature, repetitive and independent of the territory. On the contrary, a railway infrastructure must be fully integrated into the territory. In this sense, the use of the LARG paradigm allows us to overcome the limitation present in the definition of the fundamental characteristics of a large infrastructure: design characteristics are often imposed independently from the territorial context of application and from the positioning in the overall network of the infrastructure in the project. The basic elements of the decision 
to implement the HSR were taken at the level of strategic decision-making by verifying aggregate benefits and costs, as recalled in Section 2. In the project phases, the possible route alternatives are studied on the basis of the technical characteristics previously defined. In this passage, the problem that the LARG paradigm allows us to solve is hidden. If the general technical characteristics are universal, it is obviously not necessary to have a theoretical paradigm for this choice. For example, for the railway gauge, it is not possible to make choices because the technical characteristic is uniquely defined. In the case of HSR, today, there are several sets of technical characteristics that define at least three alternatives. To compare the alternatives by applying the LARG paradigm, it is necessary to highlight the characteristics of the territory crossed by the HSR line.

The High-Speed line in Southern Italy is built

(I) in regions with low GDP per capita;

(II) crossing territories with a low settlement density but having as final destination in a heavily anthropized region; and

(III) as a terminal section of the national network and, therefore, in no way modifying the capacity of the existing HSR_HC network.

All of this makes the line different from other Italian HSR lines and allows for the definition of innovative design features for the evaluation of technical and economic feasibility, design, construction, and operation.

The criteria of the hybrid LARG paradigm can be applied to the definition of modern design characteristics.

The line must be studied in a systemic vision, in which they find an adequate balance: the extent of the demand; the performances made possible by the infrastructure, the characteristics of the rolling stock, the construction, and the operating costs; the ability of the line to be resilient to infrastructural and traffic risks; the landscape characteristics of the area crossed; and the entire life cycle of the work in the application of all paradigms.

It is necessary to compare the three alternatives identified:

- Upgrades to the historical line,

- Building a new line with the characteristics of the Italian high-speed lines in terms of heavy freight trains, and

- Building a new line with the high-speed characteristics of the lines of the other countries.

\subsection{HSR Upgraded (HSR_U)}

The first alternative is the realization of the Salerno-Reggio Calabria HSR line by adapting the existing section.

The practice of upgrading is widespread and often allows for improvements in the performance of a line.

The set of upgraded historical lines (HSR_U) and new ones built is called the HighSpeed Network (HSR_N) in Italy.

Lean. The upgrading presents difficulties due to the characteristics of the current route. The line is a double track; it was initially built with a single track between 1883 and 1895, with the geometric characteristics of the time; the second track was built in the years 1960-1972, very often adhering to the existing track; only in some cases have significant variations been made. Therefore, the line has modest geometric characteristics, with high tortuosity, and would require substantial adaptation works; in practice, the reconstruction of a large part of the route is adequate at the standard of $200 \mathrm{~km} / \mathrm{h}$.

Track adjustments are difficult to make for a variety of reasons.

The orography is complex along the entire route, except for short flat stretches. The line moves near the coast, which in Calabria, at many points, is set back due to coastal erosion problems. A shift in the line inwards would affect the Apennine chain. The line often crosses densely urbanized areas.

For these reasons, an upgrade would require long durations and high costs, more than in an adaptation of a flat line because 
(1) The reduction in costs, which is usually obtained with upgrading an existing line compared with the construction of a new line would be modest due to long stretches being built in a new location;

(2) Upgrading the network in operation requires more time because the need to keep the trains running reduces the time available for construction and hinders development; and

(3) The longer duration of construction and the need for temporary work lead to further increases in costs.

Agile. The analysis of this alternative focuses on verification of modifying the demand following an upgrade in the line. The central issue to be addressed is that of the travel time between connected stations because it translates to the speed of the line.

The line in operation today is a recent line that offers excellent performance as a traditional line. The adaptation would imply a probable final result of a 20 min reduction in travel time on the entire Rome-Reggio Calabria route. In this way, the current time of the FrecciaArgento of $4 \mathrm{~h}$ and $50 \mathrm{~min}$ is reduced to $4 \mathrm{~h}$ and $30 \mathrm{~min}$, which is a less than $10 \%$ reduction in travel time. With this reduction, the connection times would be essentially the same as today, and therefore, the different demand components are essentially the same and there would be no impact on the GDP of the regions of interest except for the ones impacted by construction.

Recalling the ongoing estimation of the reduction in travel times that the adapted HSR allows, it immediately follows that the Agile paradigm is not pursued.

Resilient. Upgrading a line creates severe conditions for resilience, both during construction and, upon completion, in operation as an adapted line.

The movement of trains during construction is strongly disturbed by the need to recover time for construction and, often, long delays can occur.

The decline in quality train circulation for the entire duration of construction, together with the lack of a real alternative, creates greater isolation of Calabria and Sicily for at least a decade, as occurred during the doubling of the line in the 1960s.

The seriousness of the problems associated with the recent adaptation of the SalernoReggio motorway is significant and is paradigmatic of what would happen on the railway.

The operating problems of an upgraded line along the current route must be carefully evaluated. The coexistence of high-speed passenger trains and slow heavy freight trains, together with slow passenger trains, such as intercity and regional trains, and fast freight trains, such as logistics, and therefore essentially a strongly heterotactic circulation in all time slots would create drastic limitations to the capacity, being unable to reduce the current capacity.

Transit via high-speed trains (without stopping) in stations open to local passenger traffic would create problems regarding the safety of travelers at the station unless expensive measures are taken.

Finally, it should be noted that, on a network scale, there would be no improvement in Resilience, with only two tracks always for a Northern-Southern Italy connection.

Green. Upgrading the line with a modest reduction in travel time implies a confirmation of actual national demand on the current modes of transportation. Therefore, the annual demand from/to the three airports directly affected by the line to the South (Lamezia, Reggio Calabria, and Catania) will remain unchanged, with its heavy environmental load.

It can be concluded that, with the HSR_U, no development in GDP in Southern Italy can be triggered, as the line would perform identical functions to those today, with two negative factors: 
- Cost in the order of 10 billion for a saving of $20 \mathrm{~min}$;

- Risk in terms of regularity of the service due to the circulation of trains running at very different speeds (heterotactic circulation), from heavy goods to regional to HSR.

- Along with the negative factors, there would be some neutral ones:

- No impact on the GDP of the southern regions due to the maintenance of current travel times;

- No impact on the internal accessibility of the southern regions compared to the current situation;

- No impact on demand and, therefore, no reduction in air transport, which will indeed continue to grow with devastating economic and environmental impacts; and

- The maintenance of current times on inter-regional journeys confirming the internal non-accessibility of Southern Italy.

It is therefore highlighted that, in the studied case, not pursuing the LARG paradigm can be translated into not pursuing sustainable development, and the LARG is converging towards sustainable development. Note that, as seen in Section 3 above, the basic paradigms considered can be in conflict, from a general point of view. Often, Lean is in contrast with Agile, and in some cases, Lean is in contrast with Green.

That is, the interventions resulting from adaptation of the current line (HSR_U) would go against the sustainability of development, as defined at the international level and referred to above:

- In terms of economic sustainability, high costs and risks in the face of no change in GDP;

- In terms of social sustainability, no changes to external and internal accessibility; and

- In terms of environmental sustainability, no changes to air travel and therefore no reductions in impact.

\subsection{HSR High Capacity (HSR_HC)}

The second alternative is to build a new line with design characteristics equal to the HSR already built in Italy.

As for the upgrading, it is necessary to verify the different crucial factors for HSR by referring to the constitutive paradigms of LARG.

Lean. The Lean paradigm requires the unnecessary components of the process to be identified.

To identify the components that are superfluous for an HSR line in Southern Italy, it is necessary to analyze the traffic segments from the characteristics of the infrastructure. This is the logical sequence defined internationally [10] and nationally (PGTL 2001 [13]), PGM 2007 [55]): supply must arise from demand. The core of the Lean paradigm is thus implemented as the ability to identify and remove all that is superfluous (waste).

The new HSR_HC line in Southern Italy has a traditional line in parallel already equipped for passing heavy freight trains. Traditional lines are particularly appropriate for use by heavy freight trains and therefore offer a useful modal alternative to road freight transport. The sum of passenger trains and heavy freight trains implies a profound difference in Italian costs from European ones, with the cost per kilometer of the Italian HSR_HC up to double the average costs of French and Spanish infrastructures, as previously introduced. By eliminating the stringent technical characteristics necessary for freight traffic, heavy freight traffic is eliminated. Finally, it should be noted that waste is determined sic stantibus rebus; where there are already traditional lines useful for the traffic of heavy goods trains, in countries where there is no railway for heavy trains, the paradigm must be revised.

Agile. The speed must therefore be examined in order to identify the travel times for national and interregional journeys, which determine the possibility that the new line can resolve demand and be able to adapt to its modifications. The indications that arise from this analysis allow us to identify the level of agility that the new line has.

In the hypothesis regarding a line that can be traveled with a speed of $300 / 350 \mathrm{~km} / \mathrm{h}$, the travel time between the Strait and Rome is less than $3 \mathrm{~h}$. 
The new line designed and built with this design speed would have positive factors:

- A significant impact on the GDP of the southern regions, as previously seen from studies carried out in the areas served by the HSR, emerges experimentally within economically homogeneous areas in which there has been an increase in GDP by $7-8 \%$ in 10 years compared to areas where there is no HSR at $300 \mathrm{~km} / \mathrm{h}$;

- An impact on the internal accessibility of South Italy, with the duration of most travels between Reggio Calabria and the regional capitals, and among many other connections between provincial capitals being less than $3 \mathrm{~h}$; and

- A significant impact on the main components of demand [30,33,56]:

- by other modes (car, plane, and bus) or services (intercity and night),

- by overall increase (due to economic growth), and

- induced by the characteristics of the new system (direct due to frequency increase; indirect due to lifestyle changes).

The shift in demand with significant reduction values in the most polluted modes of the railway has a very positive impact on both the Agile and the Green paradigms.

Resilient. The building of an HSR_HC line would have positive and negative aspects with respect to resilience.

An important aspect of the construction of a new line is to create a different path to Southern Italy. This path plays an important role in terms of the network effect in the event of disasters affecting areas of Southern Italy. The new line is an alternative route to guaranteeing transportation.

From the point of view of railway traffic, the line would have all of the limits already known for the HSR_HC lines in operation. The simultaneous circulation of fast passenger trains and slow heavy freight trains implies very different speeds and therefore extreme, heterotactic behavior, which in turn implies difficulties meeting timetables and reductions in capacity. The problem is known and is one of the causes of non-use by heavy goods transportation for existing HSR_HC lines.

Green. The choice of HSR_HC alternative with heavy goods has a strong impact on the green paradigm:

- Due to the need to comply with particularly demanding technical characteristics for viaducts, both for the lengths related to the slopes and for the construction characteristics of bridges and viaducts, which must be suitable for axle loads regarding heavy freight trains;

- Due to the need to use radii for very large curves, as raising the external rail cannot be used infrequently; and

- Due to the need to build very long stations to shelter heavy freight trains that are four times longer than passenger trains.

These severe conditions have always made it difficult to build an HSR_HC and with difficulties in sharing projects with local communities, precisely because of the severe impacts of the necessary works on the territory.

\subsection{HSR Lean Agile Resilient Green (HSR_LARG)}

The factors highlighted in the previous paragraphs allow us to hypothesize a third alternative for high-speed connections between Southern Italy and the rest of the country.

It is useful to try to see if there is an alternative that maintains positive factors in agreement with the paradigms, considers the two previous macro-alternatives, and allows to resolve the negative factors.

Lean. For this paradigm, it is essential to remember a crucial fact: the traffic of heavy freight trains of $750 \mathrm{~m}$ length and 2000 tons weight was zero in the 10 years of operation of the Italian HSR_HC. Non-use by heavy freight trains occurs for a variety of reasons. The main reason is the existence of the traditional railway axis on the same corridors traveled by the HSR_HC; this allows for freed-up train time-slots in the traditional network and therefore greater ease of entry for freight trains, with a decidedly lower cost of use than 
that of the HSR_HC. For the pre-existing HSR_HC, the new line in Southern will make it possible to free up time-slots and paths on the traditional line, which already accounts for heavy freight trains.

Starting from a lack of heavy freight traffic on the HSR_HC lines built in Italy, the new line can be dedicated exclusively to passenger traffic and logistic fast freight, eliminating the superfluous (waste) traffic of heavy freight trains.

It is necessary to recall other elements that confirm the benefits of this elimination: the European vision that sees the future of railway systems as a diversification of networks [10]; the topological positioning of the infrastructure, within the Italian railway system and therefore the non-incidence in the reduction of capacity of any range of those already built, for which the modification of the characteristics of a terminal section does not reduce the capacity of the whole system already built in any way; and the existence of a large railway infrastructure along the Ionian-Adriatic corridor, identified by the EU as the main freight line within the Rail Freight Corridor 3 for routing heavy freight trains from Southern Italy, on which Italy has invested.

Another element in favor of the elimination of heavy freight trains is that light freight trains have the same characteristics as fast passenger trains, starting from the load per axle. The traffic of logistic trains 200-300 m long and weighing 500 tons is growing. Having a fast alternative for logistic freight trains is particularly important because it offers a level of utility to compete with the utility of trucks.

Creating a Lean HSR allows us to

- Maintain a low design axle load (17.5 t/ $\mathrm{m}$ with a reduction of $24 \%$ ), push slopes even up to 35 per thousand in the most critical points, and reduce the most significant construction costs (viaducts and tunnels);

- Reduce the radius of the curves, also by raising the external rail, again allowing for a reduction in costs and a simultaneous better integration into the landscape; and

- Eliminate the problem of very long stations being used for trains that are 1000$1500 \mathrm{~m}$ long.

These indications are in line with the perspective given by EIM (2008) that proposes for the High-Speed Passenger and High-Speed Logistical freight lines, with a reduction in load from 22 to $18 \mathrm{t}$. The separation between traditional and high-speed trains makes it possible to bring the historic networks involved in freight traffic to 25 tons/axis (or more) or to confirm the 22.5 tons/axis with which they were built.

The choice of the High-Speed Passenger and Logistical Freight system allows us to pursue the Lean paradigm with a drastic cost reduction, being able to reach a variable cost between one third and a half of that for the HSR_HC, as reported in Section 2.

Agile. Considering the terminal nature of the new line and considering the advances in knowledge and the experiences achieved with speeds exceeding $300 \mathrm{~km} / \mathrm{h}$, now tested on Italian lines in the range $300-400 \mathrm{~km} / \mathrm{h}$, the design speed can be set at $300-350 \mathrm{~km} / \mathrm{h}$. This speed allows us to insert the metropolitan city of Messina between connections with Rome within less than $3 \mathrm{~h}$, in the presence of a stable crossing.

An HSR without heavy goods trains allows us to carefully take care of all components of demand, being able to ensure the best pursuit of the Agile paradigm with respect to demand.

The new HSR is the definition of a passenger corridor, with high quality services, capable of functionally integrating the regions of the South (Sicily, Calabria, Basilicata, Puglia, and Campania), allowing for the creation of an economic macro-region, with territorial dimensions, population and activity, capable of producing significant developmental phenomena. The result in terms of agility will be further strengthened by the direct connection to the Lamezia Terme airport and to the port of Gioia Tauro, both nodes of the TEN-T core network and, in prospective with the Catania airport and the port of Augusta. 
Building an HSR line on the Salerno-Reggio Calabria that allows for all of the capitals of the southern peninsular macro-region to be connected in less than $3 \mathrm{~h}$ and in a little more time to the metropolitan areas of Sicily, in the presence of stable crossing, generates a decisive impact on GDP.

The economic impacts will be equally important for Northern Italy, with a formidable push towards a productive structure covering all of Italy. From the economic analyzes conducted in the last 10 years, it emerges that, for every 100 EUR invested in Southern Italy, about 40 EURs go to Northern Italy and only 50 EUR remains in the southern regions. Additionally, from this point of view, investments in Southern Italy would be great for the entire country.

The traffic will consist of trains:

- Long-distance passengers, on the Campania/Calabria/Sicily relations and the regions in Central/Northern Italy;

- Interregional passengers (Campania-Calabria-Sicily-Puglia-Basilicata);

- Regional passengers on an inter-provincial scale, serving airports;

- National logistic freight; and

- Interregional logistic freight.

It is evident that, from an analysis of the Agile paradigm, the speed $300 / 350 \mathrm{~km} / \mathrm{h}$ attracts demand for all of its uses, and therefore, it is crucial for the impact on GDP. This result is shared with the traditional HSR_HC which has the same speed as the HS_LARG.

On the other hand, the impact of the HSR_LARG is significantly different compared to the HSR_Updated line mentioned above, as the latter has times similar to the current ones and therefore demand similar to the current one and zero impact on GDP. With the speed of the line updated, the demand would remain substantially unchanged and there would be no new transportation demand from Sicily.

Resilience. The choice to build a new line allows for a significant increase in the resilience of the network with respect to serious disasters because an alternative route to the traditional one is created, thus guaranteeing connections in the event of serious damage to one of the two routes.

The use of passenger and freight trains with homogeneous speeds allows for the construction of schedules based on services with similar speeds (homotactic). This implies, on the one hand, an increase in the capacity of the line and, on the other, a high regularity of services, ensuring high punctuality and safety in the stations because all trains are of the HSR type.

Green. The HSR without heavy trains allows us to clearly implement the green paradigm that was sacrificed in the Italian HSR_HC to comply with particularly technical characteristics.

It is evident that, being able to double the slopes, the lengths of the viaducts are halved with the same geometric characteristics, with particular impact on the lean paradigm, for cost reduction, and on the green paradigm for a reduction in intrusion, with a better insertion into the landscape.

The values of the environmental impacts have been studied with different methodologies and in different contexts. The value of $\mathrm{CO}_{2}$ produced per passenger transported and per kilometer traveled over a national distance, at least greater than $500 \mathrm{~km}$, can be recalled. Investigations and models developed in the Netherlands, the United Kingdom, and Switzerland provide very strong differences between the plane and the train, in particular the high-speed one. The Swiss report [57] reported $6.4 \mathrm{~g} / \mathrm{km}$ for a train compared to $229 \mathrm{~g} / \mathrm{km}$ for a plane: that is, about 30 times. Other studies reported even greater differences, of the order of 50 times. We do not delve into the $\mathrm{CO}_{2}$ calculation models here; it is however sufficient to note that, in all literature, there is at least a ratio of 1 to 10 between trains and cars/planes. 
It should be noted that a speed of $300 / 350 \mathrm{~km} / \mathrm{h}$ allows for a difference in the green paradigm compared to the HSR_U as the train would be highly competitive with the plane, reducing the modal component of air transport from Southern Italy to Rome. This allows for a drastic reduction in environmental impacts without reducing mobility, thus producing full agreement between the agile and green paradigms, often difficult to obtain.

Once the choices have been made to achieve a Lean infrastructure, with the elimination of waste, these choices are highlighted as fully consistent when pursuing the Agile, Resilient, and Green paradigms. On this basis, an HSR without heavy goods can be synthetically identified as HSR_LARG.

\subsection{Synthetic Comparison of the Alternatives}

It is possible to present a concise comparison between the three alternatives discussed. In the previous paragraphs, we analyzed the corresponding alternative to each of the four paradigms. Now, it is possible to analyze what happens in each basic paradigm by comparing the three macro-alternatives in a transposed way. Table 5 presents the main pros and cons for each paradigm and each alternative.

Table 5. Main pros and cons for each paradigm and each alternative.

\begin{tabular}{|c|c|c|c|}
\hline Paradigm Pros/Cons & HSR_U & HSR_HC & HSR_LARG \\
\hline Lean & $\begin{array}{l}\text { Has an orography complex along the } \\
\text { entire route, and the line often crosses } \\
\text { densely urbanized areas; then, } \\
\text { upgrading would require long } \\
\text { durations for the upgrade and } \\
\text { excessive costs, more than for an } \\
\text { adaptation of a flat line }\end{array}$ & $\begin{array}{l}\text { Asks for a considerable } \\
\text { amount of costs to build } \\
\text { infrastructures with } \\
\text { characteristics that will } \\
\text { never be used because } \\
\text { (1) no heavy train uses } \\
\text { the Italian HSR_HC } \\
\text { lines, and } \\
\text { (2) Southern Italy is } \\
\text { connected by a } \\
\text { traditional line specially } \\
\text { built along the } \\
\text { Ionian-Adriatic corridor. }\end{array}$ & $\begin{array}{l}\text { Has a significantly lower cost } \\
\text { that allows us to obtain all of } \\
\text { the social benefits required } \\
\text { from the realization of the } \\
\text { HSR. Furthermore, has a } \\
\text { drastic reduction in } \\
\text { maintenance costs. }\end{array}$ \\
\hline Agile & $\begin{array}{l}\text { Attracts very modest quantities not } \\
\text { even estimable by a model; any } \\
\text { impact on GDP }\end{array}$ & $\begin{array}{l}\text { Attracts a considerable } \\
\text { amount of demand, that } \\
\text { is, at the same time, a } \\
\text { result of advanced } \\
\text { accessibility and engines } \\
\text { for new activities that } \\
\text { determine the growth of } \\
\text { GDP }\end{array}$ & $\begin{array}{l}\text { Attracts a considerable } \\
\text { amount of demand, that is, at } \\
\text { the same time, a result of } \\
\text { advanced accessibility and } \\
\text { engine for new activities that } \\
\text { determine the growth of GDP }\end{array}$ \\
\hline Resilient & $\begin{array}{l}\text { (1) does not allow for redundancies in } \\
\text { the network and } \\
\text { (2) maintains heterotactic speeds }\end{array}$ & $\begin{array}{l}\text { (1) allows for } \\
\text { redundancies but } \\
\text { (2) has heterotactic } \\
\text { speeds }\end{array}$ & $\begin{array}{l}\text { (1) allows for redundancy and } \\
\text { (2) has homotactic speeds }\end{array}$ \\
\hline Green & $\begin{array}{l}\text { (1) has a low impact on the landscape } \\
\text { (2) does not produce modal } \\
\text { modification and therefore no } \\
\text { reduction in the impacts on air } \\
\text { quality and greenhouse gases }\end{array}$ & $\begin{array}{l}\text { (1) has a heavy impact } \\
\text { on the landscape } \\
\text { (2) produces profound } \\
\text { modal changes and } \\
\text { therefore improvement } \\
\text { in air quality and } \\
\text { reduction in gases }\end{array}$ & $\begin{array}{l}\text { (1) has a low impact on the } \\
\text { landscape } \\
\text { (2) produces profound modal } \\
\text { changes and therefore } \\
\text { improvement in air quality } \\
\text { and reduction in gases }\end{array}$ \\
\hline
\end{tabular}

The Lean paradigm is first considered, and from the comparison, it can be concluded that HSR_HC respects the paradigm less as it produces a considerable amount of costs to build infrastructures with characteristics that will never be used; therefore, it is an 
overdesign [36]. Indicating the leanness of the specific alternative using L (), it results in the following:

$$
\text { L(HSR_HC) < L(HSR_U) = L(HSR_LARG) }
$$

For the Agile paradigm, the conclusion is different from that for Lean. In this case, in fact, the intercepted demand places HSR_LARG and HSR_HC at the same highest level because they attract a considerable amount of demand, while HSR_U attracts very modest quantities not even estimable by a model. Indicating the agility of the alternative using A (), it results in the following:

$$
\mathrm{A}\left(\mathrm{HSR} \_\mathrm{U}\right)<\mathrm{A}\left(\mathrm{HSR} \_\mathrm{HC}\right)=\mathrm{A}\left(\mathrm{HSR} \_L A R G\right)
$$

For the Resilient paradigm, the results are more complex. In all of the multiplicity elements of resilience, two main aspects were considered: network redundancy in the case of natural low probability and high effect events, the dispersion of train speeds (heterotacticity), and therefore, events of high probability and low effects. It can be observed that HSR_U does not allow for redundancies in the network and then is the worst in this element.

Only HSR_LARG allows for homotactic speeds, then HSR_LARG has the lowest combined Risk and the maximum Resilience.

Indicating the Resilience, considered opposite to the Risk, of the generic alternative relative to the homotactic using RS () and the Resilience relative to the redundancy using $\mathrm{RR}($ ), it can be written as follows:

$$
\begin{aligned}
& \text { RR }\left(H S R \_U\right)<R R\left(H S R \_H C\right)=R R\left(H S R \_L A R G\right) \\
& \text { RS }\left(H S R \_U\right)=R S\left(H S R \_H C\right)<\text { RS }\left(H S R \_L A R G\right)
\end{aligned}
$$

Finally, with regard to the Green paradigm, it must be considered, as already for Resilient, more aspects relating to environmental impacts. The most significant impacts are the insertion of the infrastructure into the landscape and, therefore, particularly the visual intrusion, and the improvement in air quality starting from the reduction in greenhouse gas (GHG) emissions.

The impact of the HSR_HC is particularly heavy due to the large reduction in slopes, which imply viaducts and very long tunnels, and the radii of very large horizontal and vertical curves, which imply a heavy intervention on the territory. Considering the second aspect, the HSR_U does not produce modal modification and therefore no reduction in the impacts on air quality and greenhouse gases. Indicating the opposite of levels of intrusion in the landscape using GL () and the level of reduction in GHG using GGHG (), it can be written as follows:

$$
\begin{gathered}
\text { GL(HSR_HC) < GL(HSR_U) = GL(HSR_LARG) } \\
\text { GGHG(HSR_U) < GGHG(HSR_HC) = GGHG(HSR_LARG) }
\end{gathered}
$$

It can therefore be concluded that HSR_LARG dominates in all of the paradigms while considering the main aspects. It is clear, as previously mentioned, that the in-depth examination of each element must be conducted during drafting of the feasibility project, while the need for constructing a high-speed rail line was defined during national planning.

\section{Conclusions}

At the national strategic planning level, the Italian state has decided to build an HSR line in Southern Italy. At the feasibility design level, a particularly valid support tool is the $\mathrm{ABC}$. The problem addressed in this paper is that of "which" HSR to choose, considering that, today, the term high speed identifies three profoundly different infrastructural alternatives: upgrading the existing line by increasing the speed to $200 \mathrm{~km} / \mathrm{h}$, building a new 
line with a speed of $300 \mathrm{~km} / \mathrm{h}$ with the use of heavy freight trains, and building a new line with a speed of $300 \mathrm{~km} / \mathrm{h}$ without the use of heavy freight trains.

The problem is therefore that of identifying an HSR that allows for the best results to be obtained in compliance with sustainable development, downstream of the plan decision and upstream of feasibility. To solve this problem, the LARG paradigm was proposed, which has established itself in recent years as a winning paradigm within the industry.

In summary, the LARG paradigm introduces the Resilient and Green paradigms at the same level regarding the cost and benefit objectives that can be traced back to the Lean and Agile paradigms.

The applicability of the LARG paradigm to transport systems and therefore to a large railway infrastructure was then analyzed. Moving from the theoretical proposal (Section 3) to the application example (Section 4), we conclude that the LARG allows us to examine design alternatives at the pre-feasibility level of a large railway infrastructure in an area lagging behind in development. By applying the overall paradigm, the alternative that best corresponds to the overall paradigm can be identified. It is necessary to underline that the use of the LARG paradigm introduces a new step in the decision to build a high-speed rail line. This further step makes it possible to further reduce the implications of bad choices that have economic and social repercussions for the country.

By extension, this alternative is defined in the HSR LARG Italian case study. It should be noted that this alternative is the one used in other European (France and Spain) and Asian (China and Japan) countries but is new for Italy.

The analysis carried out can be extended to all countries that are launching massive and expensive programs for the construction of high-speed rail lines or that are extending existing networks. Worldwide, in all contexts, there are always three alternatives: upgrade, build with heavy trains, and build without heavy trains.

Downstream from strategic national planning choice and upstream from feasibility, having a tool for comparison is highly important in countries that are hypothesizing or are taking the first steps towards HSR lines: from Arab countries that are setting up new lines to countries crossed by trans-Asian lines and even to the USA.

Researchers and planners may be interested in the topic covered in this paper because all EU countries are developing TEN-T rail projects using the three macro-alternatives for HSR. The proposed global paradigm makes it possible to identify and make conscious decisions, with clearly and transparently defined objectives to be pursued.

Funding: This research received no external funding.

Institutional Review Board Statement: Not applicable.

Informed Consent Statement: Not applicable.

Data Availability Statement: See referred papers, not applicable.

Acknowledgments: Special thanks to the two reviewers for their suggestions for improvements: both for the elimination and modification of existing parts, and for the insertion of new parts. Thanks to all the colleagues with whom we discussed the LARG high speed topic.

Conflicts of Interest: The author declares no conflict of interest.

\section{References}

1. UIC. 2021. Available online: https://uic.org/IMG/pdf/20210601_high_speed_lines_in_the_world.pdf (accessed on 24 July 2021).

2. OJEC. Official Journal of the European Communities. CO UNCIL DIRECTIVE 96/48/EC of 23 July 1996 on the Interoperability of the Trans-European High-Speed Rail System 1996; No L 235/6 EN 17. 9. 96. Available online: https:/ / eur-lex.europa.eu/ LexUriServ/LexUriServ.do?uri=OJ:L:1996:235:0006:0024:EN:PDF (accessed on 24 July 2021).

3. GUCE. Gazzetta Ufficiale delle Comunità Europee 17. 9. 96. N. L 235/6 IT. DIRETTIVA 96/48/CE DEL CONSIGLIO del 23 Luglio 1996 Relativa All'interoperabilità del Sistema Ferroviario Transeuropeo ad alta Velocità. 1996. Available online: https:/ / docplayer.it/188935825-C-126-e-312-gazzetta-ufficiale-delle-comunita-europee.html (accessed on 24 July 2021).

4. UIC. 2018. Available online: https://uic.org/IMG/pdf/uic_high_speed_2018_ph08_web.pdf (accessed on 24 July 2021). 
5. Krishnan, V.; Kastrouni, E.; Pyrialakou, V.D.; Gkritza, K.; McCalley, J.D. An optimization model of energy and transportation systems: Assessing the high-speed rail impacts in the United States. Transp. Res. Part C Emerg. Technol. 2015, 54, 131-156. [CrossRef]

6. Fraszczyk, A.; Lamb, T.; Marinov, M. Are railways really that bad? An evaluation of rail systems performance in Europe with a focus on passenger rail. Transp. Res. Part A Policy Pract. 2016, 94, 573-591. [CrossRef]

7. Ali, M.; Siegmann, J. Introducing high speed rail system in middle east (kingdom of Saudi Arabia): A comparison of past, current and future networks. Glob. J. Eng. Sci. Res. Manag. 2017. Available online: http:/ / www.gjesrm.com (accessed on 24 July 2021). [CrossRef]

8. Eidlin, E. Making the Most of High Speed Rail in California: Lessons from France and Germany. In Project Report of the German Marshall Fund of the United States; German Marshall Fund of the United States: Washington, DC, USA, 2015.

9. De Rus, G. Economic Analysis of High Speed Rail in Europe, Fundacion BBVA/BBVA Foundation. 2012. Available online: https:/ / econpapers.repec.org/bookchap/fbbreport/2012126.htm (accessed on 24 July 2021).

10. EIM. European Railway Technical Strategy Technical Vision to Guide the Development of TSIs. European Rail Infrastructure Manager; German Marshall Fund of the United States, Ed.; German Marshall Fund of the United States: Washington, DC, USA, 2008. Available online: https:/ / ec.europa.eu/transport/sites/default/files/themes/strategies / consultations/doc/2009_03_27_future_ of_transport/20090305_eim.pdf (accessed on 24 July 2021).

11. OJEU (Official Journal of the European Union). Regulation (EU) No 1315/2013 of the European Parliament and of the Council. 11 December 2013. Union Guidelines for the Development of the Trans-European Transport Network and Repealing. Decision No 661/2010/EU. Available online: https:/ / eur-lex.europa.eu/legal-content/EN/TXT/?uri=celex\%3A32013R1315 (accessed on 24 July 2021).

12. OJEU (Official Journal of the European Union). REGULATION (EU) No 1316/2013 OF THE EUROPEAN PARLIAMENT AND OF THE COUNCIL. 11 December 2013. Establishing the Connecting Europe Facility, Amending Regulation (EU) No 913/2010 and Repealing. Regulations (EC) No 680/2007 and (EC) No 67/2010. Available online: https:/ / eur-lex.europa.eu/legal-content/ EN/TXT/?uri=celex\%3A32013R1316 (accessed on 24 July 2021).

13. GURI. Gazzetta Ufficiale della Repubblica Italiana. Decreto del Presidente della Repubblica14 marzo 2001 . Nuovo piano generale dei trasporti e della logistica. (GU Serie Generale n.163 del 16-07-2001-Suppl. Straordinario). 2021. Available online: https:/ / www.gazzettaufficiale.it/eli/id/2001/07/16/001A6017/sg (accessed on 24 July 2021).

14. Council Presidency of Italy. Piano Nazionale di Ripresa e Resilienza. 2021. Available online: https://www.governo.it/sites/ governo.it/files/PNRR_0.pdf (accessed on 24 July 2021).

15. Chen, Z.; Xue, J.; Rose, A.; Haynes, E.H. The impact of high-speed rail investment on economic and environmental change in China: A dynamic CGE analysis. Transp. Res. Part A Policy Pract. 2016, 92, 232-245. [CrossRef]

16. Russo, F.; Rindone, C. Dalla Pianificazione alla Progettazione dei Sistemi di Trasporto; Processi e Prodotti; Franco Angeli: Milan, Italy, 2007.

17. WCED-World Commission on Environment and Development. Report of the World Commission on Environment and Development: Our Common Future. 1987. Available online: https://sustainabledevelopment.un.org/content/documents/5987 our-common-future.pdf (accessed on 24 July 2021).

18. UN-United Nations. Transforming Our World: The 2030 Agenda for Sustainable Development. 2015. Available online: https:/ / sustainabledevelopment.un.org/content/documents/21252030\%20Agenda\%20for\%20Sustainable\%20Development $\%$ 20web.pdf (accessed on 24 July 2021).

19. UN-United Nations. Global Indicator Framework for the Sustainable Development Goals and Targets of the 2030 Agenda for Sustainable Development. 2018. Available online: https://unstats.un.org/sdgs/indicators/Global\%20Indicator\%20Framework\% 20after\%20refinement_Eng.pdf (accessed on 24 July 2021).

20. Wangtu, A.X.; Jiangping, Z.; Linchuan, Y.; Ling, L. The implications of high-speed rail for Chinese cities: Connectivity and accessibility. Transp. Res. Part A 2018, 116, 308-326.

21. Rothengatter, W. Approaches to Measuring the Wider Economic Impacts of High-Speed Rail: Experiences from Europe. In Handbook on High-Speed Rail and Quality Of Life; Hayashi, Y., Ram, K.E.S., Bharule, S., Eds.; Asian Development Bank Institute: Tokyo, Japan, 2020. Available online: https://www.adb.org/sites/default/files/publication/571691/adbi-handbook-highspeed-rail-quality-life.pdf (accessed on 24 July 2021).

22. Russo, F. L'accessibilità dei servizi di trasporto passeggeri e merci. In Una nuova Accessibilità per lo Sviluppo del Mezzogiorno Servizi ed Infrastrutture di Trasporto; I Quaderni di SIPoTra/1; Ferpress Srl: Roma, Italy, 2015. Available online: https:/ / www.sipotra.it/ wp-content/uploads/2019/03/SIPOTRA-bozza-pdf-definitiva.pdf (accessed on 24 July 2021).

23. Cascetta, E.; Cartenì, A.; Henke, I.; Pagliara, F. Economic growth, transport accessibility and regional equity impacts of high-speed railways in Italy: Ten years ex post evaluation and future perspectives. Transp. Res. Part A 2020, 139, 412-428. [CrossRef]

24. Monzón, A.; Ortega, E.; López, E. Efficiency and spatial equity impacts ofhigh-speed railextensions in urban areas. Cities 2013, 30, 18-30. [CrossRef]

25. Givoni, M.; Dobruszkes, F. A Review of Ex-Post Evidence for Mode Substitution and Induced Demand Following the Introduction of High-Speed Rail. Transp. Rev. 2013, 33, 720-742. [CrossRef]

26. Chen, Z. Measuring the regional economic impacts of high-speed rail using a dynamic SCGE model: The case of China. Eur. Plan. Studies 2019, 27, 483-512. [CrossRef] 
27. Liu, X.; Schraven, D.; de Bruijne, M.; de Jong, M.; Hertogh, M. Navigating transitions for sustainable infrastructures-The case of a new high-speed railway station in jingmen, China. Sustainability 2019, 11, 4197. [CrossRef]

28. Qin, J.; Zeng, Y.; Yang, X.; He, Y.; Wu, X.; Qu, W. Time-dependent pricing for high-speed railway in China based on revenue management. Sustainability 2019, 11, 4272. [CrossRef]

29. Qin, J.; Qu, W.; Wu, X.; Zeng, Y. Differential pricing strategies of high speed railway based on prospect theory: An empirical study from China. Sustainability 2019, 11, 3804. [CrossRef]

30. Cascetta, E.; Coppola, P. High Speed Rail (HSR) induced demand models. Procedia Soc. Behav. Sci. 2014, 111, 147-156. [CrossRef]

31. Cascetta, E. Transportation System Analysis: Models and Applications; Optimization and Its Applications; Springer: Berlin/Heidelberg, Germany, 2009; ISSN 978-0-387-75857-2.

32. Hortelano, A.O.; Guzman, A.F.; Preston, J.; Vassallo, J.M. Price elasticity of demand on the high-speed rail lines of Spain: Impact of the new pricing scheme. Transp. Res. Record 2016, 2597, 90-98. [CrossRef]

33. Lubis, H.A.; Pantas, V.B.; Farda, M. Demand forecast of jakarta-surabaya high speed rail based on stated preference method. Int. J. Technol. 2019, 10, 405-416. [CrossRef]

34. Cascetta, E.; Coppola, P. Evidence from the Italian high-speed rail market. In High-Speed Rail and Sustainability: Decision-Making and the Political Economy of Investment; Taylor \& Francis: Abingdon, UK, 2017; p. 66.

35. ECA. European Court of Auditors. A European High-Speed Rail Network: Not a Reality but an Ineffective Patchwork. Special Report 19. 2018. Available online: https://www.eca.europa.eu/Lists/ECADocuments/SR19_06/SR_High_Speed_Rail_IT.pdf (accessed on 24 July 2021).

36. Beria, P.; Grimaldi, R.; Albalate, D.; Bel, G. Delusions of success: Costs and demand of high-speed rail in Italy and Spain. Transp. Policy 2018, 68, 63-79. [CrossRef]

37. Cai, S.; Yang, Z. On the relationship between business environment and competitive priorities: The role of performance frontiers. Int. J. Prod. Econ. 2014, 151, 131-145. [CrossRef]

38. Marinov, M. An Intensive Programme in Railway and Logistics. Special Issue. Res. Transp. Econ. 2014, 41, 1-2. Available online: https:/ / www.sciencedirect.com/journal/research-in-transportation-economics/vol/41/issue/1 (accessed on 24 July 2021). [CrossRef]

39. Marinov, M.; Fraszczyk, A. Curriculum development and design for university programmes in rail freight and logistics. Procedia Soc. Behav. Sci. 2014, 141, 1166-1170. [CrossRef]

40. Hussain, M.; Ajmal, M.M.; Khan, M.; Saber, H. Competitive priorities and knowledge management. J. Manuf. Technol. Manag. 2015, 26, 791-806. [CrossRef]

41. Bortolotti, T.; Boscari, S.; Danese, P. Successful lean implementation: Organizational culture and soft lean practices. Int. J. Prod. Econ. 2015, 160, 182-201. [CrossRef]

42. Purvis, L.; Gosling, J.; Naim, M.M. The development of a lean, agile and leagile supply network taxonomy based on differing types of flexibility. Int. J. Prod. Econ. 2014, 151, 100-111. [CrossRef]

43. Vinodh, S.; Devadasan, S.R.; Vimal, K.E.K.; Kumar, D. Design of agile supply chain assessment model and its case study in an Indian automotive component manufacturing organization. J. Manuf. Syst. 2013, 32, 620-631. [CrossRef]

44. Carvalho, H.; Machado, V.C. Lean, Agile, Resilient and Green Supply Chain: A Review. In Proceedings of the Third International Conference on Management Science and Engineering Management, Bangkok, Thailand, 2-4 November 2009; pp. 66-76.

45. Machado, V.C.; Duarte, S. Trade offs among paradigms in supply chain management. In In Proceedings of the International Conference on Industrial Engineering and Operations Management, Dhaka, Bangladesh, 9 January 2010; pp. 9-10.

46. Cabral, I.F. An Information Model for Lean, Agile, Resilient and Green Supply Chain Management. Ph.D. Thesis, Facultade de Ciencias e Tecnologia, Universidade Nova de Lisboa, Lisboa, Portugal, September 2011.

47. Divsalar, M.; Ahmadi, M.; Nemati, Y. A SCOR-Based Model to Evaluate LARG Supply Chain Performance Using a Hybrid MADM Method. IEEE Trans. Eng. Manag. 2020, 1-20. [CrossRef]

48. Azfar, K.R.W.A.W.; Shahzad, N.; Mumtaz, S. Application of lean agile resilient green paradigm framework on china pakistan economic corridor: A case study. Mehran Univ. Res. J. Eng. Technol. 2017, 36, 621-634. [CrossRef]

49. Cabrita, M.; Duarte, S.; Carvalho, H.; Cruz-Machado, V. Integration of lean, agile, resilient and green paradigms in a business model perspective: Theoretical foundations. IFAC Pap. Line 2016, 49, 1306-1311. [CrossRef]

50. Mingkai, B.; Shiwei, H.; Wangtu, A.X. Express delivery with high-speed railway: Definitely feasible or just a publicity stunt. Transp. Res. Part A 2019, 120, 165-187.

51. Cascetta, E.; Biggiero, L.; Nuzzolo, A.; Russo, F. A System of Within-day Dynamic Demand and Assignment Models for Scheduled Intercity Services. In Proceedings of the Seminar D\&E on Transportation Planning Methods at the 24th PTRC Summer Annual Meeting, Brunel University, London, UK, 2-6 September 1996.

52. Russo, F.; Vitetta, A. Risk evaluation in a transportation system. J. Int. J. Sustain. Dev. Plan. 2006, 1, 170-191. [CrossRef]

53. Fröidh, O.; Sipilä, H.; Warg, J. Capacity for express trains on mixed traffic lines. Int. J. Rail Transp. 2014, 2, 17-27. [CrossRef]

54. Andersson, E.; Carlsson, U.; Lukaszewicz, P.; Leth, S. On the environmental performance of a high-speed train. Int. J. Rail Transp. 2014, 2, 59-66. [CrossRef]

55. MIT. Ministero Infrastrutture e Trasporti. PIANO GENERALE DELLA MOBILITA, Linee Guida. Nota Introduttiva Roma. 2007. Available online: https:/ / trafficlab.eu/bfd_download/linee-guida-pgm-2007/ (accessed on 24 July 2021). 
56. Ben-Akiva, M.; Cascetta, E.; Coppola, P.; Papola, A.; Velardi, V. High Speed Rail Demand Forecasting: Italian Case Study. In Proceedings of the European Transport Conference, Glasgow, UK, 11-13 October 2010.

57. Tuchschmid, M. Eco Calcolatore FFS. Centro Svizzero per gli Inventari Ecologici c/o EMPA. 2010. Available online: http: / / docplayer.it/amp/15743061-Ecocalcolatore-ffs-relazione-di-base-versione-1-0-settembre-2010.html (accessed on 24 July 2021). 